
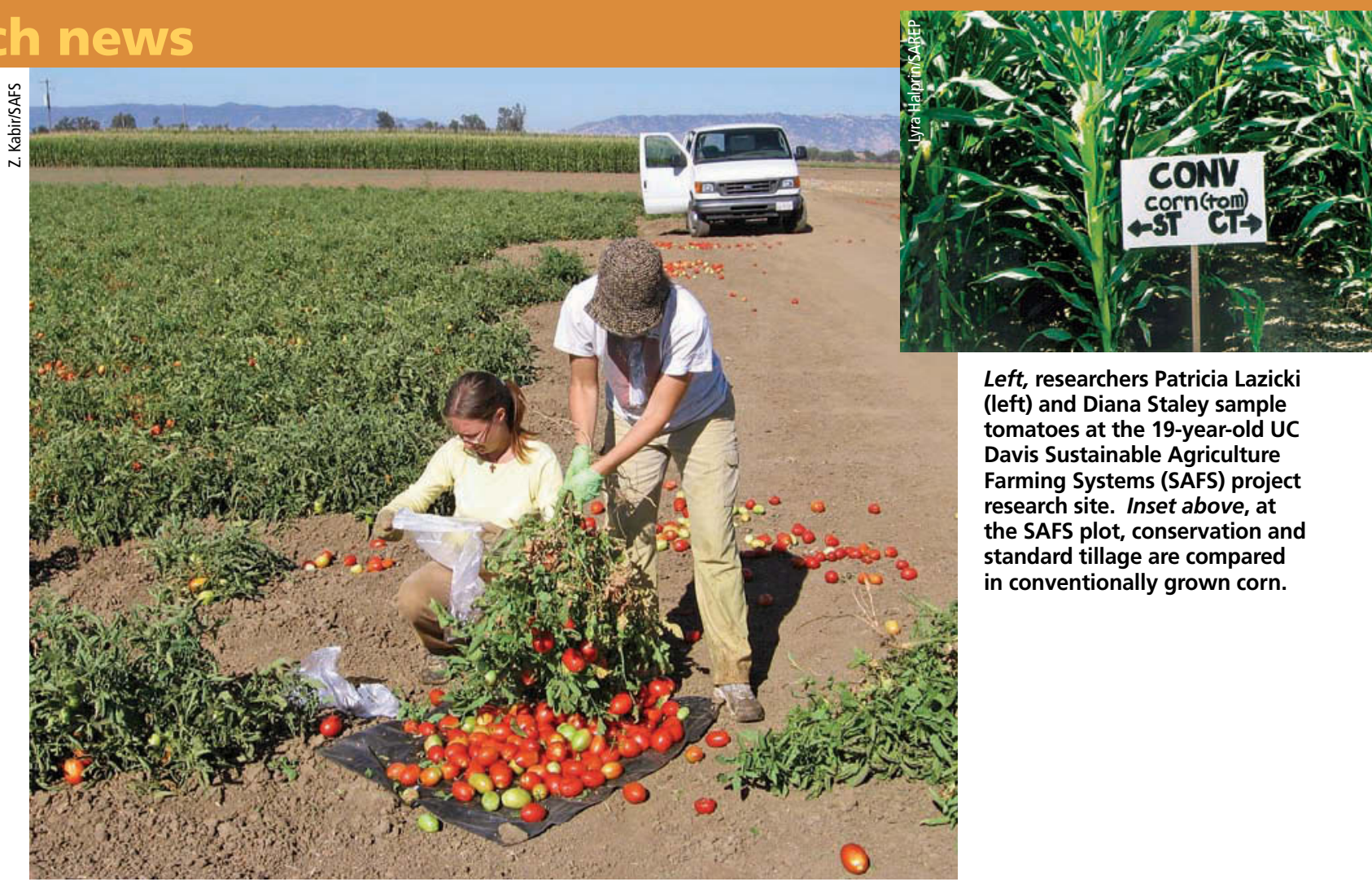

Left, researchers Patricia Lazicki (left) and Diana Staley sample tomatoes at the 19-year-old UC Davis Sustainable Agriculture Farming Systems (SAFS) project research site. Inset above, at the SAFS plot, conservation and standard tillage are compared in conventionally grown corn.

\title{
UC Davis institute focuses on sustainability
}

A recent search on Google for "sustainable agriculture" brought up more than 40 million results. And with global attention increasingly focused on related issues such as climate change (103 million results), food safety (147 million results) and food systems (224 million results), interest in sustainable agriculture - and sustainability in general — has never been greater.

One definition of sustainable agriculture is using methods that attempt to ensure the profitability of farms while preserving the environment and meeting the needs of society as a whole. UC research has reflected the world's interest in the concept, and now the numerous projects related to sustainability have a central home - the new Agricultural Sustainability Institute (ASI) at UC Davis.

"We hope to shape a forward-looking agenda for research, education, communication and engagement to support action on big, emerging issues in agriculture and the food system," says Tom Tomich, who joined ASI as director in January 2007.

ASI was originally conceived in 2005 , and jump-started with a $\$ 1.5$ million gift from the W.K. Kellogg Foundation, which endowed a chair (held by Tomich) to support the institute. ASI is intended to provide a hub that links initiatives in sustainable agriculture and food systems across all departments of the UC Davis College of Agricultural and Environmental Sciences, across UC, and with other partners throughout the state.

\section{National, global scope}

Tomich says that in addition to being a hub for UC and state partners, ASI will provide a focus for related national and international initiatives.

"Scientists and politicians around the world are now in general agreement that humans are one of the biggest forces that shape Earth's ecosystems," says Tomich, who spent the last 6 years in Nairobi, Kenya, as global coordinator of ASB, the Partnership for the Tropical Forest Margins at the World Agroforestry Center. "Research data shows that humans have transformed almost half the land area on the globe, and over half of our marine fisheries are over-exploited. Less known but frightening for the agricultural community is the fact that humans are responsible for more than half of all nitrogen-fixation, in the form of synthetic fertilizer, on the Earth."

Tomich says his goal will be to integrate activities across an evolving agenda including sustainable agriculture and the food system, plant and animal science, environmental and natural resource stewardship (see page 131), and social and economic issues.

"We intend to identify scientific principles and practices that enhance sustainable agriculture and the food system, and to produce results to meet the needs of the people of California, and, in turn, the nation and world," he says. 


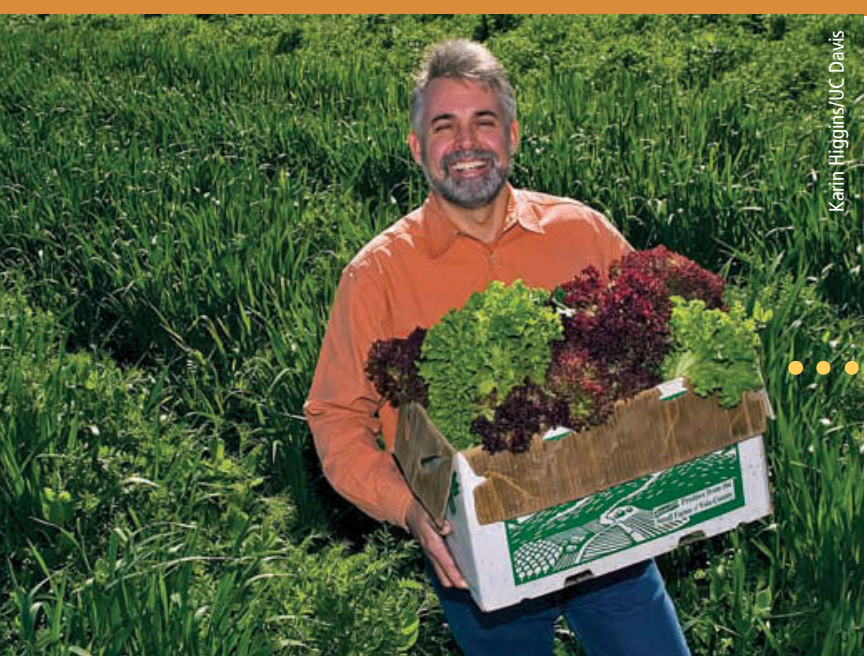

\section{Programs and projects}

At UC Davis, Tomich also serves as director of the UC Division of Agriculture and Natural Resources (ANR) Sustainable Agriculture Research and Education Program (SAREP), the first program of its kind at a land-grant university in the nation. The W.K. Kellogg Foundation has provided a \$95,000 grant to help ASI initiate and host an annual symposium series on agricultural sustainability and food systems, beginning in fall 2008.

The current programs and main projects of ASI include the 20-year-old SAREP; the 30-year-old UC Davis Student Farm, including the Children's Garden; the 17-year-old UC Davis Long-term Research on Agricultural Systems (LTRAS) project; the 19-year-old Sustainable Agriculture Farming Systems (SAFS) project; and the California Food and Fiber Futures Project (CF3).

Tomich says new sustainable-agriculture initiatives under development through the ASI include:

- Developing garden-based learning programs to improve child health and school nutrition.

- Establishing a new UC Davis undergraduate major in sustainable agriculture.

- Attracting "venture capital" for sustainability to help revitalize the SAREP grants program.

- Focusing on science in the public interest through an increased ASI endowment.

- Increasing energy intensity in the food system to help reduce carbon emissions and, in turn, global warming, with the UC Davis Energy Efficiency Center.

- Initiating a California agroecosystem assessment with benchmarks of agricultural sustainability.

"Additional discussions are under way regarding the critical issues of adaptation to climate change, and stewardship of the resource bases that sustain our food system - land, air, water, energy, people and institutions," Tomich says.
Tom Tomich, director of the Agricultural Sustainability Institute at UC Davis and the statewide UC Sustainable Agriculture Research and Education Program, will focus on emerging issues in agriculture and food systems.

Tomich is working with the SAREP staff and associated UC and Cooperative Extension personnel, ASI Interim Deputy Director Howard Ferris, eight new ASI-affiliated professorships (four hired, four currently being hired), 150 other UC Davis faculty self-identified as strongly interested in sustainable agriculture, and 150 members of UC Davis Students for Sustainable Agriculture.

\section{ANR strategic direction}

About the same time that ASI was founded, ANR formally adopted sustainability as a strategic direction. ANR has sponsored programs related to agricultural sustainability for several decades, such as SAREP, started in 1987, and the Statewide Integrated Pest Management (IPM) Program, started in 1979.

"Even though we haven't always used the term 'sustainable,' our efforts have helped growers provide adequate and dependable farm incomes, protect and enhance natural resources, reduce the use of nonrenewable resources and promote the economic viability, health and quality of life of local communities," says Rick Standiford, ANR acting vice president.

"The time was ripe for the formation of the Agricultural Sustainability Institute," Standiford adds. "University researchers are keenly interested in the serious science behind the concept of sustainable agriculture. We see great opportunities in the joint management of the systemwide SAREP program and the emerging programs of the ASI."

- Lyra Halprin and Editors

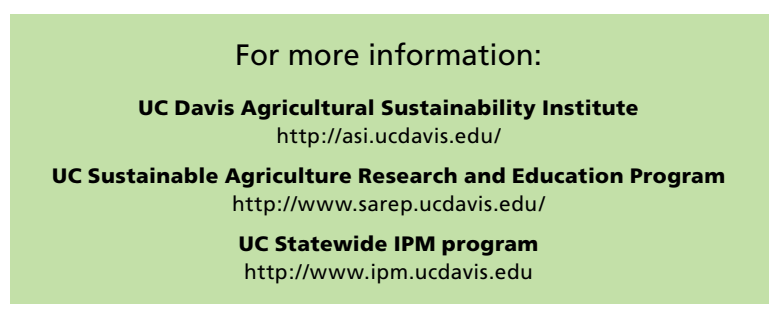

